\title{
Appropriate Value-based ICTs in support of Frontline Peacekeepers
}

\author{
Lynne Hall, \\ University of Sunderland \\ Sunderland, SR6 ODD \\ lynne.hall@sunderland.ac.uk
}

\author{
Samiullah Paracha \\ University of Sunderland \\ Sunderland, SR6 ODD \\ samiullah.paracha@sunderland.ac.uk
}

\author{
Gill Hagan-Green \\ University of Sunderland \\ Sunderland, SR6 ODD \\ gillian.hagan-green@sunderland.ac.uk
}

\begin{abstract}
This paper reports a mixed methods study with frontline peacekeepers that aimed to explore values in relation to effective peacekeeping and ICTs. A quantitative study and field visit identified that even in peace keeping areas with poor infrastructure there is considerable access to the Internet with ICT in regular and frequent use. 86 civilian and military peacekeepers participated in 11 focus groups that discussed potential ICT improvements and innovations for peacekeeping at a United Nations base. Analysis identified 4 horizontal themes (User Experience, Integration, Connectivity and Privacy) across 3 use contexts (work performance, personal physical safety and well-being). Core values were being safe, maintaining relationships, doing work well and being cared for by their organisation. Recommendations highlight the urgent need to deploy existing apps on everyday ICTs rather than any real requirements for innovation or significant R\&D spend.
\end{abstract}

\section{Digital Peacekeeping, ICTs for Peace, Military and Civilian Peacekeepers}

\section{INTRODUCTION}

United Nations Peacekeeping began in 1948 and is a unique and dynamic instrument developed by the UN as a way to help countries torn by conflict to create the conditions for lasting peace (UN Peacekeeping, 2021). More than a quarter of the world's population live in fragile, violent, and conflict-stressed environments. Peacekeepers monitor and observe peace processes in postconflict areas and assist ex-combatants in implementing the peace agreements including legitimacy, burden sharing, and an ability to deploy troops and police from around the world.

Military peacekeepers are integrated with civilian peacekeepers to address a range of mandates set by the UN Security Council and General Assembly. Although ICTs could clearly support and add value, peacekeeping suffers from several significant problems (Van Wie 2020) such as the absence of intelligence-gathering and information-processing capabilities between the field and field headquarters and the UN headquarters in New York (Salun 2019), as well as insufficient access to, and use of digital technologies (Fidler, 2015; Stauffacher et.al., 2005).
The United Nations has on average launched one peacekeeping mission a year since 1948 (Jett, 2019). Currently, 14 peacekeeping operations are underway that employ nearly 100,000 people at an annual cost of almost $\$ 7$ billion (UN Peacekeeping, 2021). Despite being backed by rich and powerful countries, the UN missions have mostly failed on their mandates (Mugabi, 2021). Since, the Brahimi Report (Brahimi et al., 2000), which argues peacekeeping has to be brought into the information age, operations have used ICTs, but struggled to capture their full capabilities (Fidler, 2015). All too often when UN peacekeepers are deployed, peace is waged by primitive or obsolete methods and devices (Dorn 2021; 2016; Shaker 2015). For example, shortcomings in modern techniques of information-gathering and early warning have accounted for many failures in UN missions (Salaün, 2019; Sigri \& Basar, 2014).

According to Wählisch (2019), the UN is still in the early stages of exploring data-driven and new technology-based solutions. Despite the benefits, the use of data and technology faces technical and operational challenges to support the peace process or crisis management (Garber \& Carrette, 2018). Limited internet access and restrictions at UN base 
camps impede digital sentiment analysis or opinion mining. Data privacy has not matured for peacekeeping, which poses ethical dilemmas (Wählisch 2019). As with many sectors, the value of data - collection and usage - is only just being recognized and applied.

Field missions often lack peacekeeping simulations to help train their soldiers (Dorn \& Dawson 2020). Nor have advances in monitoring and surveillance technology been leveraged significantly by the UN, resulting in a distinct disadvantage for the world body responsible for the maintenance of international peace and security. Further issues include inadequate training for UN peacekeepers to fulfil their mandates in counter-terrorism (Curran, 2016) with little know-how of digital technologies. Figure 1 briefly outlines this challenging context.

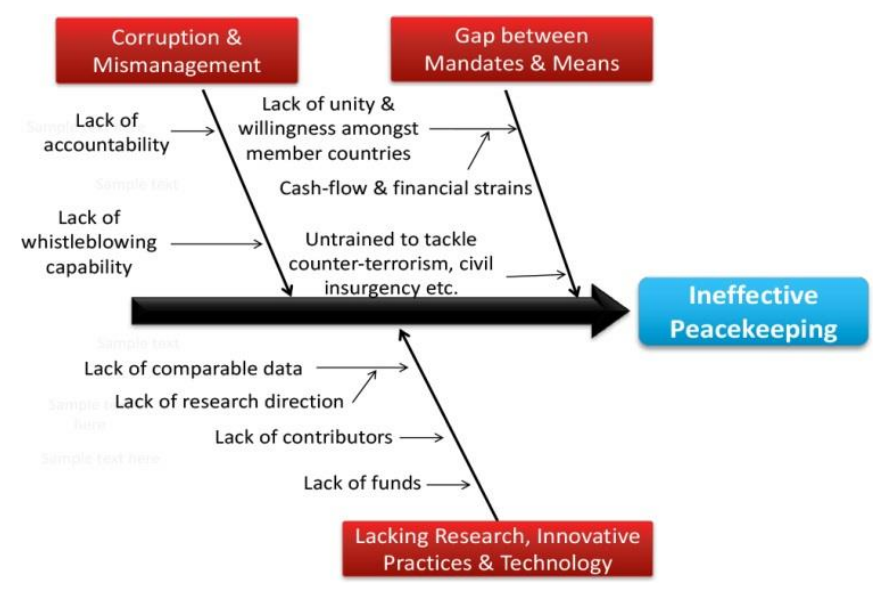

Figure 1. Fishbone Analysis: Cause and Effect

Dorn (2016) aptly remarked that the UN's power to protect depends on its power to connect. In an age when peace operations are mandated for the protection of civilians, it is essential to connect with them. Friedman \& Kahn Jr, (2003) argue that digital technologies can no longer stand apart from human values which reside with the user. Value Sensitive Design focuses on questions of human welfare, security and productivity providing a pertinent approach to consider peacekeeping. Values are at play in all spheres of envisioning, designing, developing, implementing, deploying and reinvention of ICT. Values Centred Design aims at making human values a part of technological design, research and development (Friedman, 1997; Friedman \& Kahn Jr, 2003; and Van den Hoven, 2007). It is a theoretically grounded approach to designing technology (Friedman, Kahn, \& Borning, 2006) that brings human values to the forefront of the technical design process; providing technologists, designers, and others involved in developing technology with strategies for identifying and incorporating human values into the design and development process.
By basing future ICT inventions and interventions for peacekeepers on extant human and technical values, there is a considerably greater chance for effective systems that ultimately improve peacekeeping operations. The intention of this project was ultimately to design and co-develop novel ICT solutions for effective peacekeeping, through prioritising these technical and human values. This initial study assessed the potential to introduce technologies and concepts to the field missions and to determine what values frontline peacekeepers held in relation to effective peacekeeping and ICT design.

\section{ICT FOR PEACEKEEPING}

Digital technologies can enhance people's capacity to acquire truthful information (Van Wie 2020); strengthening their resilience to cope with conflict (Bertschek, Polder \& Schulte (2019); illiteracy (Khan 2019); poor health infrastructure Tran Ngoc et al., (2018); and discovering means towards reconciliation (Al-Dajani 2020), community building, and empowerment (Ullah 2017). However, Shaker (2015) shows how outdated UN technology used to be by saying: "...if villagers wanted to alert troops that they were in danger, they had to bang their pots and pans together." According to Dorn (2021) when UN peacekeepers are deployed today, peace is waged by technologies of the 1980s or older. Advances in monitoring and surveillance technology have so far been unleveraged by the UN, resulting in a distinct disadvantage for the world body responsible for the maintenance of international peace and security.

This should not be the case in our modern globalized world with cost-effective technologies available to increase the efficiency and effectiveness of military operations so they can better achieve the ambitious mandates set out by the Security Council. Of course, innovation is not just about technology, but about people and processes as well (Dorn 2016). Ideas must percolate continually. Research and development (R\&D) need to be carried out. Field testing and pilot projects complete the R\&D cycle before procurement and deployment, but the UN has very little experience in researching, developing, and testing new technologies (Dorn 2016).

In considering the ways to maximize technology and innovation in peacekeeping, the Expert Panel on Technology and Innovation in UN Performance Peacekeeping (2014) has prioritized how technology could be leveraged for mandate implementation, including the protection of civilians; interoperability, as a prerequisite for effective operations; federated mission networks, to enable information sharing; medical support; camp and installation security; and mobile communications and information platforms. However, the UN is still 
in the early stages of exploring data-driven and new technology-based solutions (Wählisch 2019). Despite the benefits, putting data and technology to work for peace process and crisis management continues to face technical and operational challenges (Garber \& Carrette, 2018). Limited internet access and restrictions at UN base camps impede digital sentiment analysis or opinion mining. Data privacy has not matured for peacekeeping, including ethical dilemmas (Wählisch 2019).

The UN field missions lack peacekeeping simulations to help train their soldiers (Dorn \& Dawson 2020). As with many sectors, the value of data - collection and usage - is only just being recognized and applied. Such innovation is expected to be a game changer for peace operations (Hansen 2020). To encourage collaborative learning and innovation capacities across peace operations, a 3-phase research design was developed.

Peace is an important value for the HumanComputer Interaction $(\mathrm{HCl})$ research community, yet it has not resulted in the development of a research sub-community or even a research agenda (Hourcade \& Bullock-Rest, 2011). This is due to the fact that the space technology in-habits are still being debated, and the ways in which it is and can be used for peace-building and development are in flux (Firchow et al., 2017). There is a need to understand peacekeepers, in relation to how they are supported, augmented or constrained by technology, and how this may have an impact on the way we design human computer interactions. In this paper, we seek to address this void by motivating the need for $\mathrm{HCl}$ research in peacekeeping space.

As the field of Human Computer Interaction has matured, an increasing trend of $\mathrm{HCl}$ research has concerned itself with human values (Mahamuni, Kalyani \& Yadav, 2015; Borning \& Muller, 2012). At the same time, a number of approaches for systematically considering human values in information technology have also emerged (Brey, 2015; Van den Hoven, 2007). A more principled approach that can clarify issues of both theory and practice is Value Sensitive Design (Friedman, Kahn \& Borning, 2006), It is an established theory and method for addressing issues of values in a systematic and principled fashion in the design of digital technologies. While some projects have employed Value Sensitive Design (VSD) in the military space, there is a paucity of research applying VSD to design issues in peacekeeping.

The paper reports a preliminary study that assessed the potential to introduce technologies and concepts to the field missions and to determine what values frontline peacekeepers held in relation to effective peacekeeping and ICT design. The investigation aimed to design and co-develop novel ICT solutions for effective peacekeeping, through prioritising these technical and human values. The insights gained into important value dimensions of different peacekeepers and the subsequent value framework can help in closing the information gap between the system developer and peacekeepers by offering the relevant values that coincide with the value desired by the potential user. Thus, providing technologists, designers, and others involved in developing technology with strategies for identifying and incorporating human values into the design and development process. By basing future ICT inventions and interventions for peacekeepers on extant human and technical values, we hope there is a considerably greater chance for effective systems that ultimately improve peacekeeping operations.

The best peacekeeping research addresses, both, practical problems confronted by the peacekeepers and advances the development of scientific theory (Castro, 2003). This project was partly factual (thus practical), as it dealt with what peacekeepers were experiencing with ICTs and how they were responding or adapting (Harris \& Segal, 1985) to change and technological innovation. Furthermore, it also rested on normative theory as it sought to introduce change into the existing situation, either totally or partially, in order to improve the well-being of the peacekeepers and the success of their mission (Bartone et al., 1998). These two general models apply to all successful peacekeeping research (Castro, 2003); it is impossible to recommend changes for improvement unless one knows the facts on the ground. Likewise, Maslow's Hierarchy of Needs Theory (Maslow, 1943) offered valuable insights into the inner dynamics of peacekeeping, sources of conflict, and thus possible resolutions, see table 1.

Table 1: Key Characteristics

\begin{tabular}{|c|c|}
\hline Factual & $\begin{array}{l}\text { - Describe Reality } \\
\text { - Intuition } \\
\text { - Description, Categories and } \\
\text { Classification }\end{array}$ \\
\hline Normative & $\begin{array}{l}\text { - Change or Improve Reality } \\
\text { - Intuition } \\
\text { - Description, Categories and } \\
\text { Classification }\end{array}$ \\
\hline $\begin{array}{l}\text { Maslow's } \\
\text { Hierarchy of } \\
\text { Needs }\end{array}$ & $\begin{array}{l}\text { - Physiological, Security, } \\
\text { Information, } \\
\text { - Social, Motivational }\end{array}$ \\
\hline Communication & $\begin{array}{l}\text { - Simplicity, Generality and Quant } \\
\text { ability }\end{array}$ \\
\hline Design & $\begin{array}{l}\text { - Pragmatic, Grounded \& } \\
\text { Interactive } \\
\text { - Iterative, Flexible. Integrative \& } \\
\text { Contextual }\end{array}$ \\
\hline
\end{tabular}

Applying this to the specifics of ICTs entailed a communication frame that examined the: (i) channels of communication flows between the different entities; (ii) tools or platforms; (iii) spheres 
of activity; and (iv) functions that ICTs can play in promoting peace and preventing conflict (Communication for Peacebuilding: Practices, Trends and Challenges, 2011; Weaver and Shannon, 1963). In addition, design thinking or design theory (Brown \& Wyatt, 2010) provided guidance to collaborate with the stakeholders in order to innovate high-impact solutions, rigorous creativity and critical inquiry that bubbled up from below rather than being imposed from the top.

\section{METHOD}

This research was conducted with the Multidimensional Integrated Stabilization Mission in Mali (MINUSMA) established by Security Council resolution 2100 (UNSC 2013) to offer support in political and security processes, for the stabilization of the country. The mandate of MINUSMA (MINUSMA Fact Sheet, 2013) included among others: security-related stabilization tasks, protection of civilians, human rights monitoring, support to the extension of state authority in northern Mali and the preparation of free, fair and inclusive elections. MINUSMA is the fourth-largest UN operation with a personnel strength of 14,321 with 12,815 uniformed personnel and 1,342 civilian and 164 volunteer personnel (MINUSMA Fact Sheet, 2013).

The research question to be explored was "What values are important to frontline peacekeepers in relation to effective peacekeeping using ICTs." A mixed methods approach was taken including an initial quantitative survey and a MINUSMA field visit followed by 11 Focus Groups.

The quantitative survey explored demographic characteristics (age, gender, nationality), role and experience (uniformed/civilian roles, length of service, participation in prior peacekeeping missions). Participants were to be asked about their access to the internet (on base / off base / via mobile, need for internet access for work) and ICTs (generic devices and their uses (e.g. laptop, mobile) and specialist comms devices in use at MINUSMA: DECT (Digital Enhanced Cordless Tele-communications) and TETRA (Terrestrial Trunked Radio).

Focus groups were drawn from frontline peacekeepers, uniformed and civilian staff at MINUSMA. Participants were to be selected by management and engagement criteria which included being well-informed on ICT issues such as resources, ICT needs, challenges etc., as well as on the importance of digital technologies, innovation and learning in the peacekeeping space. The focus groups were semi-structured, with the following questions used to start discussions:
- How do peacekeepers envision the role of ICTs in peacekeeping operations?

- What are the most promising areas for innovation and experimentation in the peacekeeping space?

- What are creative ways in which ICTs for peacekeeping can be designed, test deployed, experimented with and scaled?

- How can UN Peacekeeping institutions be best organized for innovation and experimentation?

The Focus Groups were to be recorded and transcribed. They would be analysed using Template Analysis (King \& Brooks, 2017), an approach to thematic analysis that involves the development of a hierarchical coding template from initial data analysis that can be further refined as it is applied to the full data set (Brooks et al. 2015). Template Analysis offers the following features that made it suitable for this analysis: (i) the use of initial templates and building up; (ii) lack of prescription or hierarchical coding; (iii) ability to use a priori themes; (iv) iterative focus on trying to develop the template.

Template Analysis follows a process of reading and conducting preliminary coding on a subset of transcripts and from surrounding evidence. Critically, Template analysis allows for the definition of a priori themes and these were based on the ICT for Peace literature and from the United Nations University's online portal - Pelikan. As the initial template is applied to the data, it can be modified and reorganized as needed through repeated readings of literature and transcripts. Quality checks are included with researchers coding independently and revising their codes with the project leader and team.

\section{RESULTS}

47 participants responded to the survey. Most respondents were aged between $28-42(72.1 \%)$ and were male with only $10.6 \%$ of the sample being female. $61.7 \%$ were from Africa and $23.4 \%$ from Asia. $59.6 \%$ of respondents were uniformed peacekeepers and $40.4 \%$ civilian staff. The mean length of service at MINUSMA was 22.89 months for civilian peacekeepers and 9.39 months for uniformed peacekeepers. With longer employment, civilian peacekeepers had typically engaged in more missions than their uniformed colleagues. $95.7 \%$ of respondents had internet access via their mobile. $76.6 \%$ of respondents had access to the internet on base although only $34.04 \%$ of respondents required internet access for working purposes, with staff using facilities such as the cyber cafe. $83 \%$ were able to access the internet outside of MINUSMA.

There was good accessibility of ICTs at MINUSMA. $63.83 \%$ of respondents had laptops available to 
them. Laptops were used for research, work, selfdevelopment and entertainment. 29.78\% used DECT and $51.06 \%$ used TETRA with significantly less usage than of the mobile phone with $93.61 \%$ using the mobile phone, clearly the most popular ICT device for peacekeepers at MINUSMA. The results from the survey highlighted that the user group demographics, particularly age, with most users between 28-42, and tech-savvy. From the results, staff can already be seen to be significant ICT and internet users. The most used and thus, presumably the preferred device is the mobile phone. The survey also highlighted that the internet is available and device access ubiquitous with clear potential for providing innovation via ICTs with concerns about access removed.

Eighty-six participants took part in 11 focus groups. Five groups composed from the 30 civilians and six groups from the 56 uniformed peacekeepers participated in the discussions (with quotes identified as $M C$ and $M U$ respectively in the results). These two groups were heterogeneous in composition (incl. African, Asian, European and American) and served in different contexts and echelons of the UN missions. 10 of the civilian peacekeepers were female. All of the military peacekeepers participating were male.

As detailed in the following sections, the template analysis of the 11 sessions resulted in the identification of four horizontal themes (User Experience, Integration, Connectivity and Privacy). These were sub-themed through three contexts where staff felt that ICTs could have an impact supporting work, personal physical safety and staff wellbeing. These results are summarised in Table 2 and further discussed with illustrative quotes below. Figure 2, at the end of the results section, presents a Venn diagram depicting Design and Human values emerging from this analysis with red arrows indicating where both categories are intertwined whereas, grey arrows represent other values important for respondents.

\subsection{User Experience}

Participants identified several common attributes of positive user experiences in peace keeping contexts including simplicity, small-sized, appealing, mobility, portability, automation, smart, predictive etc. The preferred device was the mobile phone, confirming the survey results.

\subsubsection{Work Performance}

Civilian participants highlighted that "people use these [smart devices] for everything, official work and side by side... everything every feature I think we can do it with this smart device (MC-17)." Military participants criticised hard to use devices comparing them unfavourably to everyday technologies "TETRA which is very complex .... it would take you 14 to 15 minutes [to set up]...... Whereas, if you buy a phone, somebody who doesn't even know how to use the phone, is able to use it (MU-19)." Participants did recognize the value of the TETRA phone in allowing communication in emergency situations, however, it was clear that issues with its size and usability inhibited full use: "TETRA radios

Table 2: Summary of Results from Focus Groups

\begin{tabular}{|c|c|c|c|}
\hline & Work/Performance & Personal Physical Safety & Wellbeing \\
\hline $\begin{array}{l}\text { Positive User } \\
\text { Experience }\end{array}$ & $\begin{array}{l}\text { - Automation of processes } \\
\text { - Ease of existing systems: } \\
\text { COSMOS and FSS but } \\
\text { - Challenges with Umoja } \\
\text { impacting on morale and } \\
\text { staff productivity }\end{array}$ & $\begin{array}{l}\text { - Size and portability issues } \\
\text { with TETRA } \\
\text { - Simple devices for } \\
\text { emergency reporting }\end{array}$ & $\begin{array}{l}\text { - Personal development } \\
\text { - Connection with family } \\
\text { - Medical emergency reporting }\end{array}$ \\
\hline Integration & $\begin{array}{l}\text { - Consolidation of different } \\
\text { platforms } \\
\text { - Shared info across } \\
\text { departments }\end{array}$ & $\begin{array}{l}\text { - Centralized dashboards } \\
\text { - Situational awareness } \\
\text { - Quicker, more accurate } \\
\text { responses }\end{array}$ & $\begin{array}{l}\text { - Simple integrated health } \\
\text { records } \\
\text { - Crowd-sourced info for basics } \\
\text { around the city } \\
\text { - Easier onboarding }\end{array}$ \\
\hline Connectivity & $\begin{array}{l}\text { - Remote Office } \\
\text { - Network issues }\end{array}$ & $\begin{array}{l}\text { - Situational awareness } \\
\text { - On the ground } \\
\text { communication }\end{array}$ & $\begin{array}{l}\text { - Connecting with family and } \\
\text { friends } \\
\text { - Boosting morale } \\
\text { - Network issues }\end{array}$ \\
\hline Privacy & $\begin{array}{l}\text { - Access issues } \\
\text { - Data sharing }\end{array}$ & $\begin{array}{l}\text { - Cyber-security } \\
\text { - Data protection }\end{array}$ & $\begin{array}{l}\text { - Confidentiality } \\
\text { - Issues with misuse of } \\
\text { information }\end{array}$ \\
\hline
\end{tabular}


are good, they are best ... but, if it could still be a little bit smaller (MC-21)".

Participants, like any users, wanted a simple system that would be easy to setup and intuitive to use: "a solution where you just have a radio with the features of a satellite instead of having all these gadgets installed (MC-19)." Automation of basic processes was proposed in all groups, from troubleshooting "you just click one button and then it executes all these commands every time and it fixes it. So, it saves 2 to 30 minutes to sending out security alerts (MC-2)." Some participants already had positive experiences of automated alert systems with one participant no longer receiving "phone calls ten times a day from ten different people for the same question (MC-22)." The medium in which alerts were provided was also raised by military participants: "When you are driving like $5 \mathrm{~km}$ and you have this broadcast after two minutes of your departure, how are you going to read it? (MC-9)". ICTs were highlighted in some groups as having potential for the transfer of medical information and related gains in health staff performance, with participants keen to extend this to support work: "scan the fracture in the ambulance, send ... so that they'd know earlier that this case is coming and they could respond to it properly (MUG-6)".

\subsubsection{Personal Physical Safety}

Several groups discussed how having simple, portable and small ICTs would enhance physical safety in risky situations. Participants provided examples of what they would prefer: "Simple powerful handsets ... go on patrol everything secured ... having a facility that gives us emergency like the Tetra radio frequency (MU-27)." Wearables were proposed by some groups as a potential way to enhance physical safety: "you don't even have to press it [watch] to send an alarm ... it has to sense your level of anxiety (MC-27)". A key innovation to improve physical safety was by ensuring all staff were aware of alerts, such as assaults on the base, was proposed in several groups: "everybody, disregarding level, disregarding the contract structure, disregarding the type of work should be in a single loop, to at least to be alerted at the same time these types of alert come in (MC-27)".

\subsubsection{Wellbeing}

ICTs were reported as contributing to peacekeepers' wellbeing in different ways. A key factor for staff was being able to easily and regularly connect with families and friends via ICT: "I have a little child ... she gets to feel that she is actually seeing her parent, because here it is a non-family duty station (MC-27)."

Others highlighted their use of ICT for recreation and enjoyment: "For me mobile phone is my fun ICT (MC-14)." Participants also highlighted the potential for ICTs to support self-development: "with new technologies' scope we never stop learning ... improving personal development (MU-23)." ICTs were also viewed as having a key role in supporting staff health and welfare: "it would be really cool, if we had an ICT system that cares about me as an individual... and even if I'm moving across missions, this is the information that the doctors have (MC27)."

\subsection{Integration}

Integration, or rather the lack of integration, emerged as a key theme, with a need for systems to be centralized, for information to be shared and applications consolidated.

\subsubsection{Work Performance}

The productivity and holistic performance of individuals and the organization can be improved through an increase in system integration. The recent launch of Umoja system, designed to help the UN Missions streamline recordkeeping, workflow, and communications among its myriad departments, infuriated some participants who were struggling to master the complex system: "who says its easy or user-friendly? Rather, l'd say it is fundamentally a flawed system... It is damaging both our morale and productivity (SUB-2)." "I find Umoja system nonintuitive, labour-intensive and full of glitches and distractions (NICTP-3)." The majority of civilian participants who used back-office systems raised issues related to a lack of integration of basic information, requiring duplication of effort. Participants identified that integrated facilities would improve the productivity and efficiency of the UN mission. Participants explained how different offices often use different applications so when people move from duty station to another: "they struggle to again learn another application to do the same job (MC-20)." Groups also expressed frustration over the current on-boarding process: "your information is supposed to be transferred but you are still required to do all your input again. There is lot of forms and you have to fill it up, have to scan it, you have to load it (MC-21)".

Some groups discussed the need for integration between departments, "so the work of human rights could be integrated with the work of political affairs and this means sharing information on you know just basic [information] (MC-35)". However, in addition to the lack of information sharing, there was a recognition that participants were unaware of what was available: "we don't have a comprehensive solution because we don't understand the problem because we can't see even what we have (MU-15)." Were staff able to share information and data participants felt that it would enhance their problemsolving capabilities at work: "Imagine the power ... quantifiable to say that this area needs more police assistance, more guys going to help them or I have 
more human rights violations; maybe I need more legal aid (MU-15)."

\subsubsection{Personal Physical Safety}

Many participants were of the view that integrated data and access to real-time data can improve personal physical safety: "we need a tool that help us integrate information as quickly as possible and make us able to synchronize (MU-23)." Proposals included centralised dashboards to highlight incidents and show no-go zones or to track the current situation of a convey and "in case of incident they would send feedback automatically and alert the respective departments involved (MC24)." Participants had seen and were positive about existing systems: "[Track 24] can be integrated into whatever system that personnel are given, what vehicles are given. It alerts you, okay you are in the no-go zone, better get out of there (MC-7)." Similarly, proposals for planning and making UN security information more accessible included an app that was "a map and then the actual security of UN updates - information saying that this particular road is off limits today (MC-14)."

\subsubsection{Wellbeing}

Groups also discussed ways in which integrated systems could help with common issues they face that relate to but are not exactly work. Several expressed the need for consolidated medical records and a system to help keep track of appointments and medical history: "having a kind of repository let's say with all the[health] information that the person [can] carry with him also (MC-24)."

Another common suggestion from participants was a mobile application or resource centre that could easily crowd-source information from the staff on basics for life in the city: "this kind of system to support the human life, if it can be developed it would be great (MC-25)." Participants identified that this could be especially helpful for new employees while they are on boarding: "....where to eat, where to get staff, these kinds of basic things for example it can be connected with an information package and it should be available from day one of the mission (MC-20)." Again, some participants had already experienced systems that provided support: "in Darfur it was very easy because we used to have an app like that (MC-19)." Participants from the military-side of the mission raised challenges in accessing common cultural knowledge held by the civilians: "[civilian staff] have been here for three years in the mission. They will have a breadth of knowledge, but that breadth of knowledge is here (pointing to his head), it's not on a document, it's not shared (MU-15).

\subsection{Connectivity}

A key issue for participants was connectivity. Whether it was for communicating with the rest of their force or with their families, having a stable way of connecting was seen as essential for their work performance, personal physical safety and wellbeing. Currently, network issues remain a big hurdle whether for work or in allowing members to communicate with their families.

\subsubsection{Work Performance}

Connectivity brought significant communication benefits in the work context, allowing staff: "to chat all over the world with other UN missions and I can also connect via internet to contact, to chat with my projects (MC-16)." The UN like other organisations is moving to the cloud: "The UN is becoming more accessible via the internet you have more and more apps that are in cloud that's the direction we are heading (MC-7)." Several civilian participants brought up the idea of a "remote office" in which they would be able to connect to the office and solve issues remotely. This in turn would allow them to handle work more efficiently while providing them with flexibility in terms of location. Proposals included: "manage systems remotely... you can monitor how the parameters, how the packets are going to and fro, instead of you rushing back to the office, just log in ... and you can fix them remotely (MC-19)."

Connection issues were seen as limiting work performance: "if you have network problems, it is not possible to share your documents (MC-36)" and also were often a harbinger of significant issues: "sometimes we have emergency situations and we don't know if the government want to kill the network (MC-36)." Participants were positive about systems that could work offline as well as relying on connectivity such as the Field Suit Support system, "which is really very user-friendly even without network it always works through most of the time (MC-34)."

\subsubsection{Personal Physical Safety}

For some participants being "able to communicate [emergencies] all the time" was important "for the sake of our security (MC-3)." Participants identified that physical safety could be enhanced by greater integration of information when calling in physical alerts: "the other information that they need from you, what is your location, who you are and all those things, the technology could help to give them immediately (MC-24)." Military participants highlighted the need for instant communications with troops on the ground or security forces at the base: "we have patrol but in addition to that, we could have CCTV, ... moving of personnel from this point to that point could be monitored through the CCTV and if something, they will come to action rapidly (MC-9)."

ICTs were seen as a way to provide greater support in action, reducing the dangers and uncertainty: "there are situations you forget everything... [if] they are monitoring these things from the room and then 
they will come out for the action immediately ideally (MC-9)." Military participants felt that all the different troops in mission should be connected with a universal network, whether the person was on foot patrol or vehicle patrol: "We are completely blind at certain moments, which is really uncomfortable position to be in. You have to make crucial decisions, you know, time critical on information that is not there. ... we are talking about people's lives here (MU-13)."

\subsubsection{Wellbeing}

When speaking about the need to stay connected, both civilian and military participants brought up video calling their families as a way of alleviating some of the strains of working in the mission. This need to ensure connection with families was highlighted by those who managed others, "they need to make a real good effort in making sure that these people are able to reach out back to their families (MU-13)." And "the mission affects family men and if you are in a mission you should stay connected to your family. The mission should think or UN should think how to keep people connected to their families (MU-25)." Connecting with families and friends was seen as key to boosting morale: "because of this ICT we are able to constantly get in touch with our family that making life a little better than if we hadn't heard from them (MU-51)." For many participants, connecting with their family members was listed as one of their most favourite uses for ICTs. And the most popular technologies were smartphones: "I carry it all the time, so that's the most used item in ICT. I use it for emails, I use it to for the news, I communicate with family and friends and also for work related (MC-14)."

\subsection{Privacy}

With regards to privacy, cyber security and secure data, connections were seen as lacking in current ICTs. Several participants were concerned about being hacked or having information intercepted. However, there were no actual experiences of such problems reported.

\subsubsection{Work Performance}

With information sharing, there were several issues with transparency and privacy settings. However, concerns lay not in the use of ICTS but rather on the protocols about future information use and sharing: "Basically, I work on information. Some sections give information you don't want to share with other sections. It's quite sensitive because the information you give becomes national (MU-45)."

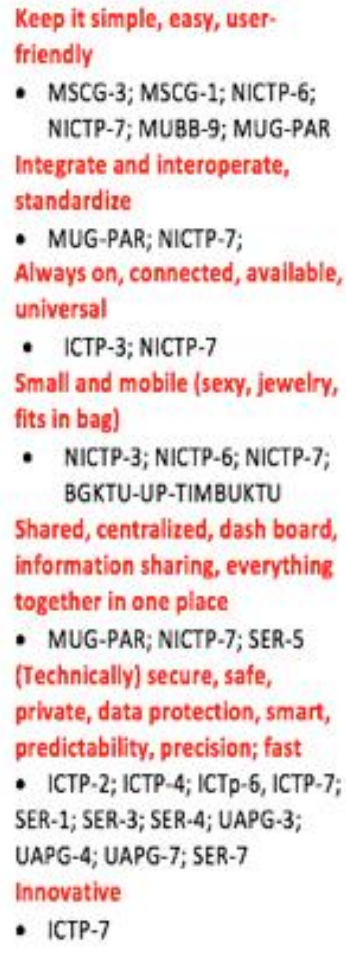

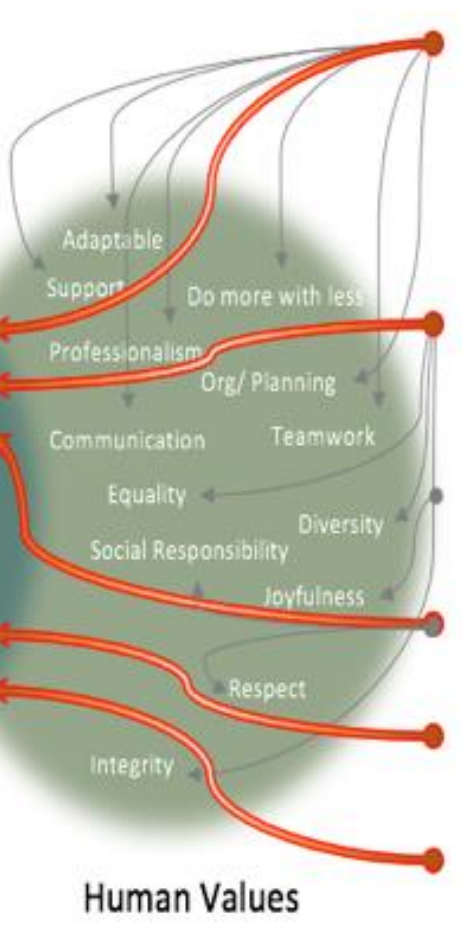

Efficient, flexible, competent, professional

- MSCG-3; MSCG-1; MSCG-2; NICTP-1; NICTP-6; NICTP-7; MUBB-9; ICTP-1; ICTP-7; ICTP5; SER-1; NICTP-3; ICTP-4; SER-3

Fair, diverse impartial,

transparent, integrity

- UAPG-4; UAPG-3; MSCG-3; SUB-2; NICTP-7; NICTP-1; UAPG-7; MSCG-4; ICTP-8; MSCG-5; NICTP-3; UAPG-8 Good health and wellbeing, low stress

- MSCG-3; SER-5 Welfare, familly, community

- MUG-PAR; ICTP-7; ICTP-6; ICTP5; ICTP-2; NICTP-7; SER-5 (Personally) Safe, secure, private, locatable

- NICTP-7; MUG-PAR; ICTP-3; ICTP-4; UAPG-7; SER-4 Innovation

- ICTP-7; NICTP-7

Figure 2 - Venn Diagram of intertwined values

Cybersecurity was raised in all groups: "Without data protection there's no way to have fairness. Because, if I send information to someone that, surprise, is lost and someone is there to hack this information, it's 
not fairness in the ICT (MU-46)." A lack of awareness was also flagged: "[major issue] work wise, is ICT security. I have to teach my clients I have to tell them the basics of how to protect their data (MC-4)."

\subsubsection{Personal physical safety}

Although both civilian and military participants could see the benefits of monitoring and surveillance, these benefits also raised issues: "But then, tracking everyone, I think it is a bit of a privacy, a human privacy issue (MC-25)." The transition to online and digital raised issues for some participants who were concerned about the security of their personal data: "yeah, from a cyber protection or security point of view... a big gap that could be filled (MC-7)."

\subsubsection{Wellbeing}

The most common concern from participants when discussing information and surveillance was the importance of confidentiality and making sure that information was not misused: "But it is not only the confidentiality of the things I have seen in the past that there has been a misuse by managers (MC24)."

\section{VALUES \& RECOMMENDATIONS}

The main values that emerged from the Focus Groups that should help to tailor ICT adoption and use strategies for missions such as MINUSMA are provided in figure 2 and summarised into four main themes as detailed in the following sections, ending with recommendations.

\subsection{Being Safe}

Safety was the most important and a core value for self, others and the mission. Multiple layers of safety enabling ICTs were identified, from the automatic panic button to the provision of up-todate and timely geographical information in the field. Safety was a ubiquitous value, of importance at all times and in all places. A key facet was the constant sense of danger that emerged with UN missions based in unsafe environments, in contexts that evoke fear. This, in itself, is profoundly unhealthy for staff. However, it could be reduced through providing all staff with several means that made them safer, such as the sending out of allperson alerts on everyday devices. With safety the core value for the majority of staff, it is critical that existing and proven technologies, some already in use in other missions in the UN are deployed in all contexts thereby saving lives.

As well as physical safety, there was also the quasitraditional values and unsubstantiated concerns about cybersecurity. As with physical safety it is the sense of imminent and potential danger that pervades the value. Informing staff in induction about excellent ICT security, etc. and the protocols for information sharing should aim to establish a valid sense of security. Notably, values related to ICT/data security were limited to the work context, with almost no concerns about personal data security. Even the focus on health records and appointments was fundamentally related to work, as being regularly medically assessed is part of the job.

\subsection{Maintaining Relationships}

The potential to maintain relationships was one of the main values for participants. ICTs were seen as already adding value to maintaining relationships, meeting the need to communicate with family, friends and colleagues. Beyond ensuring access to internet and devices (almost all staff have a smartphone) there is no need to develop technologies or applications to support this, as they are all mainstream, already available and being used.

\subsection{Doing Work Well}

Working well was intrinsically linked with safety and increasing automation that impacted on safety, such as health information provision across bases and all-staff alerts. Beyond safety, working well, was frequently frustrated by the lack of integration of information and systems. There was also a lack of training via online or digital approaches. Engaging with everyday apps and technologies highlights what should be possible and has raised participants expectations.

\subsection{Being Cared for by UN}

This sense of care could be manifested through targeted onboarding and in particular, information continuity, so that personal information, such as health records, followed staff across missions and bases. In additional organisational care requires the establishment of appropriate practices for information sharing, data access and training.

\subsection{Recommendations}

Based on this analysis, the following recommendations were made to inform future design decisions in ICT development and deployment at the MINUSMA base and in other similar contexts.

1. To adopt individual personal mobile devices as the prevalent platform on which to develop ICTs for staff. This should include the use of mobile apps for work purposes as well as for information provision, health, onboarding, communication, and most importantly as a way to receive alerts.

2. To improve personal physical safety through increased situational awareness, achieved 
through increased integration of information and data sharing further supported through surveillance ICTs such as sensors and cameras. Providing centralized dashboards indicating safe/unsafe zones, allowing ways of reporting emergencies in a simple and efficient manner, and providing easier onthe-ground communication are seen as key. Wearables that provide information on where staff are, that can be 'pushed' to register concerns and that can sense if you need support and are unable to ask for help would seem an appropriate future direction.

3. To integrate and consolidate information and systems, increasing automation where possible, with automated approaches to health information provision across bases and all-staff alerts essential. In parallel, to establish appropriate practices for information sharing, data access and use with training via mobile phones.

Although ICTs are becoming visible in peacebuilding literature, yet there has not been any overarching account that hold out human values with ethical import as a central design criterion for peacekeeping. In this study, we have offered such an account, emphasizing VSD theory and method to enhance the digital peacekeeping in which values arise, encompassing not only the wellbeing of peacekeepers, but also their work-related productivity and security. As mentioned in Britt \& Adler (2003): 'the proper study of peacekeeping is the peacekeeper......the human dimension factors may either improve or slow down the wellbeing or performance of the peacekeepers.' It implies that we should focus on peacekeepers' values vis-à-vis technical design which are determinants of improved performance. The goal of Digital Peacekeeping is to create an enabling environment for peacekeepers that maximally improves their well-being as well as their capacity to function efficiently and effectively in the conflict-zones. This can only be achieved if the human and value dimension of the frontline peacekeepers is given due consideration.

\section{CONCLUSION}

Understanding how technology can be used for sustainable peace and social change is essential (Firchow et al., 2017). With technology, an "amplifier of human intent" (Toyama 2011) expanding the base of knowledge increases the understanding of the circumstances under which technology amplifies peace supporting a holistic discussion of the ways that technology can impact contentious social and political processes. The study reported in this paper highlights that the core values for frontline peacekeepers are: safety, relationships and the reciprocity of doing work well for an organization that cares for them. Providing ICTs that meet all these values does not need to wait for technological advances, rather everything needed already exists. Appropriate, value-based ICTs will increase user ability to focus on their peacekeeping roles, feeling safe, loved and cared for, something clearly essential in a conflict zone.

\section{ACKNOWLEDGEMENTS}

We sincerely thank UNDFS-ICTD and the UNU-CS for assisting this field research at the UN MINUSMA in Mali. We are also immensely grateful to the frontline peacekeepers, both uniformed and civilian, deployed at Bamako and Gao bases for sharing their ideas with us to improve peacekeeping.

This work was partially supported by the Creative Fuse North East project exploring how technology can be used to support diverse sectors.

\section{REFERENCES}

Bartone, P.T. et al. (1998). Dimensions in psychological stress in peacekeeping operations. Military Medicine, 163(9), 587- 593.

Borning, A., and Muller, M. (2012). Next steps for value sensitive design. In: Proc. CHI '12, ACM, 1125- 1134.

Brahimi, L., et al. (2000). Report of the Panel on United Nations Peace Operations. A/55/305S/2000/809. New York: United Nations General Assembly.

Brey P. (2015) Design for the Value of Human Well-Being. In: van den Hoven J., Vermaas, P., van de Poel I. (eds) Handbook of Ethics, Values, and Technological Design. Springer, Dordrecht. https://doi.org/10.1007/978-94-007-6970-0 14

Britt, T.W., \& Adler, A.B. (Eds.), (2003). The psychology of the peacekeeper: Lessons from the field. Praeger Publishers, Westport, Conn.

Brown, T., Wyatt, J. (2010). Design thinking for social innovation. Stanford Social Innovation Review, (Winter). Retrieved from https://ssir.org/articles/entry/design thinking for social innovation

Bushe, G.R. (2013). The appreciative inquiry model. In E.H. Kessler, (ed.) Encyclopedia of Management Theory, (Volume 1, pp. 41-44), Sage Publications.

Castro, C. A. (2003). Considerations When Conducting Psychological Research during Peacekeeping Missions: The Scientist and the Commander. In B. T. Litz, \& A. B. Adler (Eds.), 
The Psychology of the Peacekeeper. Westport, CT: Praeger, Pp. 11-27.

Communication for Peacebuilding: Practices, Trends and Challenges. (2011). Search for Common Ground with support from USIP.

Curran, D. (2016). More than Fighting for Peace? Conflict Resolution, UN Peacekeeping, and the Role of Training Military Personnel. New York: Springer.

Dorn, A. W., \& Dawson, P. F. (2020). Simulating Peace Operations: New Digital Possibilities for Training and Public Education. Simulation \& Gaming, 52(2), 226-242. https://doi.org/10.1177/1046878120968605

Dorn, A.W. (2021). A Technology Innovation Model for the United Nations: The "TechNovation Cycle”. UN Unite Paper 2021(1). $<$ https://walterdorn.net/pdf/Tech-InnovationModel-for-UN_UnitePaper-2021-1_Dorn_202101-27.pdf>

Dorn, A. W. (2016). Smart Peacekeeping: Towards Tech-Enabled Operations. IPI, Providing for Peacekeeping No.13.

Fidler, D. (2015). Can UN Peacekeeping Enter the Digital Age? Council on Foreign Relations, 2015. Retrieved from http://blogs.cfr.org/cyber/2015/07/02/can-unpeacekeeping-enter-the-digital-age/

Firchow et al. (2017). PeaceTech: The Liminal Spaces of Digital Technology in Peacebuilding. International Studies Perspectives 18(1): 4-42.

Friedman, B., Kahn, P. H., Jr., and Borning, A. (2006). Value Sensitive Design and information systems. In P. Zhang and D. Galletta (eds.), Human-computer interaction in management information systems: Foundations, 348-372. Armonk, New York; London, England: M.E. Sharpe.

Garber, K., Carrette, S. (2018). Using technology in fragile, conflict, and violence situations: Five key questions to be answered. Washington, DC: World Bank.

Gowan, R. \& Andersen, L.R. (2020). Peacekeeping in the shadow of Covid-19 era: Short-term responses and long-term consequences. DIIS Policy Brief. https://www.diis.dk/en/research/peacekeepingin-the-shadow-of-covid-19-era.

Harris, J.J and Segal, D.R. (1985). Observations from the Sinai. Armed Forces \& Society 11:235248.

Hourcade, Juan Pablo, Bullock-Rest, Natasha E. (2011). HCl for peace: a call for constructive action. In: Proceedings of ACM CHI 2011 Conference on Human Factors in Computing
Systems, 2011,. pp. 443-452. https://dx.doi.org/10.1145/1978942.1979005

Jett, D. (2019). Why UN Peacekeeping Missions Fail. The Globe Post. https://theglobepost.com/2019/08/01/unpeacekeeping

King, N. \& Brooks, J. (2017). Doing template analysis: a guide to the main components and procedures. In Template analysis for business and management students (pp. 25-46). SAGE Publications https://www.doi.org/10.4135/9781473983304

Maslow, A.H. (1943). "A theory of human motivation". Psychological Review. 50 (4): 37096.

Mahamuni, R., Kalyani, K., Yadav, P. (2015). A simplified approach for making human values central to interaction design. Procedia Manuf.3, 874-881.

MINUSMA Fact Sheet (2013). Supporting political process and helping stabilize Mali. UN Peacekeeping.

https://peacekeeping.un.org/en/mission/minusma

Mugabi, I. (2021). Why UN peacekeeping missions have failed to pacify Africa's hotspots. Mad for Minds. $\quad$ https://www.dw.com/en/why-unpeacekeeping-missions-have-failed-to-pacifyafricas-hotspots/a-57767805

PIERSKALLA, JAN, AND FLORIAN M. HOLLENBACH. 2013. "Technology and Collective Action: The Effect of Cell Phone Coverage on Political Violence in Africa." American Political Science Review 107: 207-24.

Salaün, N. (2019). The Challenges Faced by U.N. Peacekeeping Missions in Africa. The Strategy Bridge. $\quad \mathrm{https}: / /$ thestrategybridge.org/thebridge/2019/10/14/the-challenges-faced-by-unpeacekeeping-missions-in-africa

Sigri, U and Basar, U. (2014). An Analysis of Assessment of Peacekeeping Operations. The Korean Journal of Defense Analysis. Vol. 26, No. 3, pp. 389-406.

Shaker, N. (2015). UN peacekeeping needs a major technological update. QUARTZ. <https://qz.com/509351/un-peacekeepingneeds-a-major-technological-update/>

Scaturro, G. (2016). Tech for peace: Facts and figures. SciDevNet. https://www.scidev.net/global/features/tech-forpeace-facts-and-figures.

Toyama, K. (2011). Technology as amplifier in international development. Paper presented at the iConference 2011, February 8-11, 2011, Seattle, WA, US. 
Tran Ngoc, C., Bigirimana, N., Muneene, D. et al. Conclusions of the digital health hub of the Transform Africa Summit (2018): strong government leadership and public-privatepartnerships are key prerequisites for sustainable scale up of digital health in Africa. BMC Proc 12, $17 \quad$ (2018). https://doi.org/10.1186/s12919-018-0156-3

UN Peacekeeping (2021). What peacekeeping does? <https://peacekeeping.un.org/en>

UNSC. (2013, April 25). Resolution 2100 (2013). http://www.un.org/en/peacekeeping/missions/mi nusma/documents/mali\%20_2100_E_.pdf

Van den Hoven, J. (2007). ICT and value sensitive design. The Information Society: Innovation,
Legitimacy, Ethics and Democracy in Honor of Professor Jacques Berleur SJ, 67-72.

Wählisch, M. (2019). Big Data, New Technologies, and Sustainable Peace: Challenges and Opportunities for the UN. Journal of Peacebuilding \& Development, 15(1), 122-126. https://doi.org/10.1177/1542316619868984.

Weaver, W., and Shannon, C.E. (1963). The Mathematical Theory of Communication. Univ. of Illinois Press.

WEIDMANN, NILS B. 2015. "Communication Networks and the Transnational Spread of Ethnic Conflict." Journal of Peace Research 52: 285-96. 